\title{
El fenómeno de la traducción del lenguaje soez a través del subtitulado en la dirección español > italiano: un análisis contrastivo a partir de la serie Alguien tiene que morir
}

\author{
Giuseppe Trovato \\ Università Ca’ Foscari Venezia \\ giuseppe.trovato@unive.it
}

\section{Resumen}

El objetivo de este trabajo es estudiar la traducción de una serie de palabras y expresiones con carácter soez y malsonante mediante el proceso de subtitulación en la dirección español > italiano. Se trata de un fenómeno muy interesante, ya que la traducción del lenguaje vulgar es un campo de investigación poco explorado hasta ahora. Nuestro interés radica en analizar el tratamiento traductológico de determinadas palabras y expresiones generalmente clasificadas como soeces y/o vulgares en el marco del subtitulado entre dos lenguas afines. Las conclusiones serán interesantes en cuanto a los resultados del trasvase interlingüístico y a cómo se concibe la vulgaridad en las dos lenguas examinadas.

Palabras clave: Traducción, lenguas afines (español-italiano), subtitulado, lenguaje soez, serie de televisión Alguien tiene que morir.

Abstract. The phenomenon of the translation of foul language through subtitling in the Spanish> Italian direction: a contrastive analysis from the series Alguien tiene que morir

The aim of this paper is to study the translation of a series of swear words through the process of subtitling in the Spanish > Italian direction. This is an extremely interesting phenomenon, since the translation of vulgar language is a field of research that has not yet been explored very much. Our interest lies in analysing the translatological treatment of certain words and expressions generally classified as foul and/or vulgar when it comes to subtitling between two related languages. The conclusions will be interesting in terms of translation results and how vulgarity is conceived in the two languages examined.

Keywords: Translation, cognate languages (Spanish-Italian), subtitling, vulgar language, TV series Alguien tiene que morir. 


\section{Introducción}

La expresión del lenguaje denominado vulgar, soez o malsonante ${ }^{1}$ representa sin duda un ámbito de investigación extremadamente fértil, pero al mismo tiempo bastante desatendido ${ }^{2}$, ya que parece darse una tendencia generalizada a creer que se trata de un asunto muy delicado, susceptible de herir sensibilidades, dependiendo de las tradiciones culturales de los individuos. Efectivamente, como observa Fuentes Luque (2014, p. 3), este tipo de lenguaje se configura como una temática tabú que plantea límites lingüísticos, sociales y culturales. Sin embargo, es innegable que en los últimos tiempos la adopción de palabras y expresiones cargadas de una dimensión vulgar se ha venido extendiendo cada vez más, incluso en situaciones de comunicación menos informales. Al hilo de lo anteriormente mencionado, resulta interesante estudiar este fenómeno desde un punto de vista contrastivo y traductológico, con el fin de observar cómo el lenguaje soez es concebido en la pareja de idiomas implicada en el acto traductor y qué cambios potenciales pueden sufrir los términos y expresiones malsonantes. En el caso que nos ocupa, la combinación lingüística será español-italiano y, más concretamente, en la dirección español $>$ italiano ${ }^{3}$. El análisis que llevaremos a cabo se basa en un corpus creado a partir de la miniserie televisiva hispano-mexicana distribuida por Netflix titulada Alguien tiene que morir creada por Manolo Caro y conformada por 3 episodios. Concretamente, tomaremos en consideración las transcripciones realizadas a partir del proceso de subtitulación hacia el italiano y compararemos los resultados del rastreo traductológico con la versión original en lengua española que también ha sido objeto de transcripción ${ }^{4}$.

\section{Breves notas sobre el lenguaje soez en el ámbito de la traducción y de la lexicografía monolingüe y bilingüe}

Cuando hablamos de lenguaje soez, términos o palabras malsonantes, vulgares, groseras y/o ofensivas, hacemos referencia a un fenómeno que por lo general

1. En el presente estudio usaremos sin distinción y como sinónimos los adjetivos: vulgar, soez, malsonante, grosero y ofensivo. En ocasiones, nos referiremos al fenómeno lingüístico objeto de nuestro artículo con la etiqueta taco(s) o vulgarismo(s).

2. A este respecto, cabe señalar que se ha empezado a realizar algún acercamiento a esta temática, si bien queda mucho camino por recorrer. Véase la muy reciente tesis doctoral defendida en la Universidad de Valladolid por Dilia Di Vincenzo en 2020 y titulada Análisis contrastivo español-italiano de términos y expresiones malsonantes en el registro coloquial del lenguaje cinematográfico. Su autora se propone estudiar las diferencias existentes entre el uso de palabras y expresiones malsonantes en el habla coloquial de las lenguas española e italiana, mediante los diálogos fílmicos, la observación de los contextos comunicativos de los guiones cinematográficos y el estudio de las intenciones de los actos de habla groseros.

3. Resultan muy escasos los estudios en torno al subtitulado entre lenguas afines como son el español y el italiano. A este respecto, una reciente y significativa aportación procede de Beatrice Garzelli (2020): La traducción audiovisual español-italiano. Películas y cortos entre humor y habla soez, publicada en la editorial Peter Lang.

4. La actividad de transcripción, tanto de los subtítulos en italiano como de la versión original 
se sigue considerando como un tabú (Fuentes Luque, 2014; Zamora Muñoz, 2015), como algo que no se puede nombrar o tratar a causa de determinados prejuicios o en razón de las convenciones impuestas por la sociedad en la que vivimos.

El fenómeno antes aludido tiene importantes implicaciones en el ámbito tanto lingüístico como traductológico, pues contamos con algunos estudios científicos que se ocupan concretamente de analizar el tratamiento de determinadas palabras o expresiones de carácter soez o vulgar, conocidas en el ámbito coloquial mediante la etiqueta 'tacos'. Hace más de veinte años, se habían ocupado del lenguaje grosero en el ámbito de la traducción fílmica Pavesi y Malinverno (2000). Las autoras basaban sus reflexiones en películas en lengua inglesa dobladas para el público italiano y apuntaban a una dimensión emotiva y afectiva en el uso de palabras y expresiones malsonantes. En especial, es interesante observar cómo se lleva a cabo su trasvase interlingüístico entre lenguas consideradas afines, como son el italiano y el español. En este sentido, son relevantes los estudios llevados a cabo por Zamora Muñoz (2015; 2016; 2018). La línea común de estas contribuciones estriba en el análisis traductológico de algunos vulgarismos ${ }^{5}\left(c a z z o\right.$, minchia $\left.^{6}\right)$ en el doblaje fílmico. Desde este punto de vista, cabe señalar que la variación lingüística puede llegar a desempeñar un papel realmente significativo en las elecciones traductológicas que el traductor decide efectuar. En un estudio reciente relativo a la traducción hacia el español de la prosa de Andrea Camilleri, Trovato (2019, p. 371-372) centra también su atención en la traducción del término minchia que el diccionario Treccani califica como una lexía de procedencia meridional y la marca como vulgar. La correspondencia adoptada en la traducción en lengua española es "carajo", una palabra que el Diccionario de la lengua española (DLE) clasifica como malsonante y el diccionario Clave como vulgar y malsonante. Ahora bien, volviendo a las consideraciones de Zamora Muñoz, el estudioso constata que el equivalente acuñado es la técnica traslativa predominante, lo cual tiende a garantizar la norma de la fidelidad lingüística. Efectivamente, siguiendo la propuesta taxonómica de Molina y Hurtado (2002) el equivalente acuñado consiste en la utilización de un término o expresión reconocidos como equivalente en la lengua meta, bien por el diccionario, bien por el uso lingüístico. Se observa, por tanto, un fenómeno de estandarización a la hora de la transposición interlingüística, ya que el italiano y el español cuentan con un distinto nivel de matización del lenguaje soez, como veremos en lo sucesivo. Asimismo, Zamora Muñoz (2016, p. 318) señala que en varios casos el significado de los vulgarismos disfemísticos se vacía en el plano semántico y se carga pragmáticamente en el discurso. Será, pues, el contexto el elemento determinante a la hora de marcar el nivel de ofensa o transgresión de un término vulgar con

en español, ha corrido a nuestro cargo.

5. Cabe precisar que los estudios realizados por Pablo Zamora Muñoz analizan el tratamiento traductológico de los vulgarismos en la dirección italiano > español.

6. En el caso de minchia, estamos ante un vulgarismo marcado diatópicamente, fenómeno que puede complicar el proceso de traducción. 
respecto a lo que se considera como norma lingüística estándar. En una línea similar, en un estudio de hace casi veinte años, Toledano (2002) abordaba la obscenidad en relación con la traducción, fenómeno condicionado por el contexto social en el que surge y adquiere visibilidad.

De todos modos, resultan más cuantiosos y de tradición consolidada los estudios dedicados a las marcas de uso en el ámbito de la lexicografía, tanto monolingüe (Calvo Rigual, 2003; Cundín Santos, 2002; Garriga Escribano, 1994; 2019; Gordón Peral, 2010; Nomdedeu Rull, 2011) como bilingüe (Bermejo Calleja, 2016; Castillo Peña, 2007). En efecto, la marcación tiene mucha relevancia de cara a ofrecer al usuario traductor las pautas —ojalá — oportunas sobre la utilización correcta de palabras y expresiones desde la perspectiva de su uso social y pragmático. El uso apropiado de una palabra o expresión depende de varios factores, generalmente asociados al contexto de comunicación. En este sentido, Castillo Peña (2007, p. 56) pone de relieve que las formas vulgares están muy marcadas con respecto a la lengua estándar y se reconocen con facilidad, con independencia del nivel de lengua que se use. No obstante, en ocasiones los criterios adoptados para la correcta marcación diatópica, diafásica o diastrática no siempre están bien clasificados y definidos, de ahí que resulte difícil fiarse de los diccionarios a pies juntillas, sobre todo en lo relativo a la actividad de traducción.

\section{Objetivos del trabajo, metodología y corpus de análisis}

El objetivo principal del presente estudio radica en la identificación de las correspondencias traslativas en lengua italiana de una serie de palabras y expresiones soeces y malsonantes, a partir de la miniserie televisiva hispanomexicana distribuida por Netflix titulada Alguien tiene que morir, creada por Manolo Caro y conformada por 3 episodios ${ }^{\top}$. La serie está ambientada en el año 1954 en una España conservadora y tradicional durante la época franquista donde la temática sexual, entre otras cuestiones, se configuraba como un auténtico tabú. Resulta, por lo tanto, interesante observar y estudiar qué tratamiento se realiza del fenómeno de la traducción del lenguaje soez y vulgar a través del proceso de subtitulación y qué tendencias se vislumbran en el panorama actual.

Metodológicamente, una vez efectuadas las transcripciones de los diálo$\operatorname{gos}^{8}$ por lo que se refiere a la versión original en español y de los subtítulos

7. No entra dentro de los objetivos del presente trabajo repasar la teoría y metodología de la subtitulación, pues se han publicado muchos estudios al respecto. Realizaremos algunas referencias cuando sea necesario y oportuno de cara al fenómeno abordado en nuestro artículo.

8. Nos urge aclarar que, a la hora de la transcripción de la versión en español, se han mantenido las pausas, las interrupciones y los solapamientos presentes en la versión original. Por lo que se refiere a la versión en italiano, se ha efectuado la transcripción de los subtítulos distribuidos por Netflix. 
proporcionados y distribuidos por Netflix en lo que a la versión italiana atañe, contamos con los siguientes resultados:

\begin{tabular}{|l|l|l|}
\hline Episodios & $\begin{array}{l}\text { Número de palabras } \\
\text { en español }\end{array}$ & $\begin{array}{l}\text { Número de palabras } \\
\text { en italiano }\end{array}$ \\
\hline 1 Soltar la presa & 4929 & 4266 \\
\hline 2 Tomar puntería & 3998 & 3443 \\
\hline 3 Apretar el gatillo & 3619 & 3135 \\
\hline Total de palabras & 12546 & 10844 \\
\hline
\end{tabular}

Tabla 1 - Número de palabras de la versión en español y de la versión subtitulada en italiano de la miniserie Alguien tiene que morir

Como es de esperar a raíz de las limitaciones espacio-temporales impuestas por el subtitulado (Díaz Cintas, 2001; 2008), el número de palabras en la versión italiana es inferior frente a la versión original española. De todos modos, el fenómeno de la compresión no conlleva una diferencia especialmente relevante; se trata de 1702 palabras menos en la versión subtitulada y, sin embargo, se trata de una tendencia en línea con los postulados teórico-metodológicos de esta modalidad de la traducción audiovisual.

Los términos y expresiones vulgares que se han localizado tras emprender el rastreo traductológico son los siguientes. Los enumeramos según el número de casos detectados:

\begin{tabular}{|l|l|}
\hline Término / expresión & Número de ocurrencias \\
\hline Maricón & 16 \\
Maricones & 6 \\
\hline Puta & 6 \\
\hline Cońo & 4 \\
\hline Mierda & 3 \\
\hline Me cago en ... & 2 \\
\hline Joder & 2 \\
\hline Cojones & 2 \\
\hline Carajo $(s)$ & 1 \\
\hline Culo & 1 \\
\hline Marica & 1 \\
\hline Total & 44 \\
\hline
\end{tabular}

Tabla 2 - Términos y expresiones vulgares y malsonantes localizados en la miniserie Alguien tiene que morir

Son en total 44 las voces y expresiones malsonantes y vulgares identificadas. En el apartado posterior, daremos cuenta de las correspondencias traductológicas que cada término o expresión ha recibido a raíz del proceso de subtitulado. 


\section{Resultados del rastreo traductológico}

En este apartado, pretendemos dar cuenta de la parte más práctica del presente estudio, es decir, la identificación de las correspondencias de traducción que hemos localizado tras llevar a cabo el rastreo traductológico. A partir de los resultados obtenidos, será posible formular algunos comentarios en torno a las posibilidades que ofrece la lengua italiana a la hora de trasladar del español el lenguaje soez y vulgar.

A continuación, proporcionamos los datos lingüísticos recabados señalando mediante cursiva las palabras o expresiones objeto de análisis:

\begin{tabular}{|l|l|}
\hline Versión en espańol (original) & Versión en italiano (subtitulada) \\
\hline Pues yo no diría que es maricón, ¿eh? & Non lo credevo un finocchio \\
\hline Gabino es un maricón & Gabino è un finocchio \\
\hline Mi hijo no es maricón & Non è un finocchio \\
\hline $\begin{array}{l}\text { No te conviene seguir relacionándote } \\
\text { con un maricón }\end{array}$ & Non dovresti frequentare un frocetto \\
\hline $\begin{array}{l}\text { No soy maricón, pero si tuviera que } \\
\text { estar con alguien, estaría con una } \\
\text { mujer, no con una nińa }\end{array}$ & $\begin{array}{l}\text { Non sono un frocetto, ma, se stessi con } \\
\text { qualcuno, starei con una donna, non } \\
\text { con una bambina }\end{array}$ \\
\hline Tu hijo es maricón, Gregorio & Tuo figlio è un finocchio \\
\hline $\begin{array}{l}\text { Yo pensé que el único que se necesitaba } \\
\text { era ser maricón }\end{array}$ & Credevo bastasse essere finocchio \\
\hline Ven, aquí. Baila, maricón. & Vieni qui. Balla, finocchio \\
\hline Maricón. ¡Espósenlo! & Finocchio. Ammanettalo! \\
\hline De todo menos de maricón. & Di tutto, tranne essere finocchio \\
\hline He denunciado al maricón de su hijo. & Ho denunciato il figlio finocchio \\
\hline Y¿el otro maricón? & E l’altro finocchio? \\
\hline $\begin{array}{l}\text { Qué tonta fui. Es frágil, pero maricón. } \\
\text { Debí sospechar que vendría con el } \\
\text { cuento }\end{array}$ & $\begin{array}{l}\text { Fui proprio una stupida. È fragile, ma è } \\
\text { anche un finocchio. Dovevo sapere che } \\
\text { l'avrebbe raccontato }\end{array}$ \\
\hline $\begin{array}{l}\text { Levanta el arma. Maricón. Eres un } \\
\text { arma, maricón! ¡Levanta el arma! } \\
\text { arma el }\end{array}$ & $\begin{array}{l}\text { Alza il fucile. Finocchio! Sei un } \\
\text { finocchio! Alza il fucile. Alzalo, finocchio! } \\
\text { Alza il fucile! }\end{array}$ \\
\hline $\begin{array}{l}\text { Qué va. Tampoco ha sido para tanto. } \\
\text { Coged el jabón, maricones }\end{array}$ & $\begin{array}{l}\text { Non è andata così male. Raccogli il } \\
\text { sapone, finocchio }\end{array}$ \\
\hline Qué Lázaro y Gabino son maricones & Che Lázaro e Gabino sono finocchi \\
\hline ¿es como tenía razón? Maricones. & $\begin{array}{l}\text { Senti, i finocchi come te dovrebbero } \\
\text { stare sottoterra }\end{array}$ \\
\hline
\end{tabular}




\begin{tabular}{|l|l|}
\hline Callad, maricones & Zitto! \\
\hline Hay maricones con suerte. & Alcuni sono fortunati \\
\hline ¡Me cago en la puta! & Porca puttana. \\
\hline Me cago en tu puta madre. & Per l'amor del cielo! \\
\hline Esas putas tienen más dignidad qué tú & Questi scarafaggi hanno più dignità di te \\
\hline Abre la puta boca. Ahí, traga & Apri quella cazzo di bocca. Ecco, ingoia. \\
\hline Es un hijo de puta & Ė un figlio di puttana \\
\hline Santos es un hijo de puta & Santos è un figlio di puttana \\
\hline ¡Sube! ¿Quién ayuda, coño? & $\begin{array}{l}\text { Venite qui! Qui non aiuta nessuno? } \\
\text { Porca puttana. }\end{array}$ \\
\hline $\begin{array}{l}\text { No seas pesado, coño. Te estoy } \\
\text { ofreciendo una oportunidad para } \\
\text { reformar tu vida. }\end{array}$ & $\begin{array}{l}\text { Non fare il difficile. Ti sto offrendo la } \\
\text { chance di cambiare la tua vita. }\end{array}$ \\
\hline ¿Qué coño haces? & Chi credi di essere? \\
\hline Vamos, al suelo. Al suelo, coño. & A terra! A terra, maledizione! \\
\hline $\begin{array}{l}\text { Vaya mierda de partido. La tenía que } \\
\text { haber dado una patada. }\end{array}$ & $\begin{array}{l}\text { Una partita di merda. Dovevi dargli un } \\
\text { calcio. }\end{array}$ \\
\hline $\begin{array}{l}\text { ¿Qué haces tú, imbécil? No me vuelvas } \\
\text { a tocar en tu vida. Mexicano de mierda. }\end{array}$ & $\begin{array}{l}\text { Come osi? Stronzo. Non toccarmi mai } \\
\text { più. Mai più, dannato messicano. }\end{array}$ \\
\hline Vete a la mierda. & Fottiti \\
\hline $\begin{array}{l}\text { Joder. Amigo. Si sales, ¿yo te puedo } \\
\text { pedir un favor? }\end{array}$ & $\begin{array}{l}\text { Cazzo. Amico. Se uscirai, mi faresti un } \\
\text { favore? }\end{array}$ \\
\hline $\begin{array}{l}\text { Joder, cómo chillan esas cerdas. Ni en } \\
\text { una matanza. ¿De dónde vienen las } \\
\text { nuevas, señor? }\end{array}$ & $\begin{array}{l}\text { Dannazione, come strillano quei maiali! } \\
\text { Peggio di un mattatoio. Da dove } \\
\text { vengono quelle nuove? }\end{array}$ \\
\hline ¡Me tienes hasta los cojones! & Sono stufo di queste stronzate! \\
\hline ¡Abre, cojones! & Dannazione! Apri quella bocca. \\
\hline ¿Qué carajos te pasa? Te estoy hablando. & $\begin{array}{l}\text { Che diavolo ti prende? Sto parlando } \\
\text { con te. }\end{array}$ \\
\hline $\begin{array}{l}\text { Los maricones como tú deberíais estar } \\
\text { ya todos tragando tierra. Te podemos } \\
\text { acusar de mil cosas. Algunas llevan } \\
\text { pena de garrote o empalado por el culo. }\end{array}$ & $\begin{array}{l}\text { Senti, i finocchi come te dovrebbero } \\
\text { stare sottoterra. Possiamo accusarti di } \\
\text { qualsiasi cosa. Potremmo impiccarti o } \\
\text { impalarti. }\end{array}$ \\
\hline Espera. Yo quiero ver al marica bailar. & Aspetta. Voglio vederlo ballare \\
\hline
\end{tabular}

Tabla 3 - Resultados del rastreo traductológico a partir de la miniserie Alguien tiene que morir 


\section{Comentario traductológico}

Traducir el lenguaje soez no es en absoluto una tarea fácil. Ahora bien, a la hora de emprender el proceso traductor, una contribución valiosa debiera proceder del diccionario. Sin embargo, los diccionarios no siempre son de gran ayuda en este sentido. De hecho, como apunta Fontcuberta i Gel (2001), las soluciones traductológicas que los repertorios lexicográficos ofrecen son a menudo neutras y no reflejan realmente las intenciones comunicativas de los hablantes.

En relación con nuestro corpus de análisis, como se puede notar, el término soez más utilizado es maricón, pues es la homosexualidad la temática principalmente abordada en la miniserie, considerada tabú en la España de los años 60 del siglo pasado, una España franquista cerrada y conservadora. Si acudimos a los diccionarios monolingües DLE y Clave, nos damos cuenta de que las dos obras lexicográficas califican el término abordado respectivamente como "despectivo, malsonante, insulto" y "vulgar, despectivo, se usa como insulto". Por lo que se refiere a las correspondencias de traducción, el término más empleado en los subtítulos es finocchio. Este término está marcado como vulgar en el diccionario de la lengua italiana Treccani y como vulgar y despectivo ${ }^{9}$ en el Grande Dizionario Italiano Hoepli. De todas maneras, observamos que se dan dos casos en los cuales la traducción se concreta en la correspondencia frocetto, elección probablemente determinada por razones de tipo pragmático (Cf. Bazzanella, 2020: 22). Se trata del diminutivo italiano del término frocio. El diccionario Treccani señala que esta palabra tiene un origen etimológico incierto, la marca como vulgar y ofrece una indicación de tipo diatópico, pues señala su uso como típico del área romana. Por su parte, causa cierta sorpresa notar que el Grande Dizionario Italiano Hoepli no menciona en absoluto la vertiente vulgar o malsonante de este término; se ciñe a etiquetarlo como dialectal y de uso romano.

Dos expresiones típicas del espańol peninsular presentes en la serie tratada "me cago en la puta" / "me cago en tu puta madre" reciben en un caso la traducción mediante la exclamación algo injuriosa porca puttana, pero sorprendentemente, en el otro caso, la expresión se matiza con Per l'amor del cielo!, una locución interjectiva que suele expresar contrariedad e impaciencia. De todas maneras, esta expresión no posee ninguna carga vulgar en italiano. Podemos, pues, afirmar que en este último caso se produce un fenómeno de atenuación de la expresión vulgar o malsonante. En esta circunstancia también, es posible barajar la hipótesis de que las soluciones traductológicas están determinadas por cuestiones de naturaleza pragmática y expresiva (Orrù, 2020: 67), que en determinados casos llevan a la atenuación del alcance vulgar en la lengua meta.

En cuanto al tratamiento traductológico de puta, resultan interesantes dos casos. En uno, se usa para hacer referencia a las cucarachas (scarafaggi): se les 
dirige este insulto por ser bichos molestos ("Estas putas tienen más dignidad que tú"). En ambos idiomas, es muy común calificar de forma vulgar algunos animales o insectos que despiertan una sensación de asco. En este caso concreto, en italiano en "Questi scarafaggi hanno più dignità di te" se atenúa la dimensión vulgar presente en la versión española mediante el nombre directo de esta clase de artrópodos y se adopta como técnica de traducción la particularización (Cf. Hurtado Albir, 2011: 269). En el segundo caso, estamos ante un empleo muy común en el español peninsular, o sea, el uso como adjetivo antepuesto a un sustantivo para indicar descontento o fastidio, de ahí que la expresión abre la puta boca se convierta en italiano en apri quella cazzo di bocca.

Pasemos ahora a la expresión vulgar y malsonante coño, usada para indicar extrañeza, sorpresa, admiración o disgusto. Es interesante analizar este término en contraste con la lengua italiana. En este sentido, la versión en línea de $I l$ Grande Dizionario di Spagnolo Zanichelli la marca como vulgar, ofreciendo como equivalente general de traducción fica. Además, añade como equivalente la palabra italiana masculina $c a z z o$, señalando su valor pleonástico. Cabe asimismo notar su valor como interjección (¡qué coño! = $e$ che cazzo.). Así pues, según esta fuente lexicográfica, en el proceso traslativo del español al italiano debería producirse el paso del género femenino al masculino, aun manteniéndose en el ámbito de los órganos genitales.

De los cuatro casos identificados, solo uno remite a nivel traductológico al carácter vulgar de dicha expresión (porca puttana). En un caso ("No seas pesado, coño") no se ha traducido, quizás por las limitaciones espacio-temporales impuestas por el subtitulado. En otro caso (¿Qué coño haces? = chi credi di essere?), se pierde la dimensión grosera del original. En la cuarta ocurrencia, se adopta una opción traductológica acertada (maledizione), si bien aquí también se desvanece el carácter vulgar. De hecho, el diccionario Treccani señala que esta exclamación interjectiva expresa rabia, contrariedad, descontento.

Es interesante analizar ahora los casos en los que se producen fenómenos de ligera atenuación con respecto a la versión original. Los mencionados casos se manifiestan tanto en la expresión "mexicano de mierda" que se traslada al italiano mediante dannato messicano, como en la interjección vulgar y malsonante "joder" que es traducida como dannazione. Tanto el participio con función adjetiva (dannato) como el sustantivo (dannazione), desde el punto de vista de las técnicas de traducción pueden considerarse como calcos del inglés (damn, damnation) y se perfilan como rasgos típicos de otra modalidad de la traducción audiovisual, esto es, el doblaje. A este respecto, como apunta Rossi (2010), la lengua del doblaje es la creación más original de la historia lingüística del cine y se ha difundido de manera amplia gracias a la exposición del público a las películas americanas adaptadas. En este sentido, ningún italiano usaría en sus intercambios conversacionales espontáneos las expresiones antes abordadas. Sin embargo, la lengua empleada en el cine ha permitido una difusión bastante rápida de dichas expresiones, de ahí que los calcos del inglés se hayan convertido en un fenómeno de atenuación lingüística. 
La expresión muy cargada a nivel vulgar “iMe tienes hasta los cojones!” se matiza en italiano a través de "sono stufo di queste stronzate!" cuyo uso en lengua italiana se sitúa en un plano más coloquial. Algo parecido puede decirse a propósito de “¿Qué carajos te pasa?” donde el elemento de vulgaridad se pierde en la lengua meta, pues en la versión italiana se elabora la siguiente formulación "Che diavolo ti prende?". En este caso también, podemos afirmar que se trata de una expresión característica de la lengua del doblaje que no se corresponde con un uso lingüístico auténtico. Estamos ante lo que Rossi $(2006 ; 2010)$ define en lengua italiana como doppiaggese ${ }^{10}$, es decir, una variedad lingüística típica de las películas dobladas. Una vez más, notamos la influencia que ejerce la lengua inglesa en la traducción fílmica, como señala entre otros Pavesi (2006).

Por otra parte, un caso de casi idéntica correspondencia entre los dos idiomas lo tenemos con la locución "empalarte por el culo", traducido por impalarti. En esta ocasión, en italiano se puede prescindir del sustantivo "culo", pues la forma verbal lleva aparejado el significado vulgar con un trasfondo sexual.

Teniendo en cuenta una de las taxonomías de las técnicas traslativas más acreditadas en campo traductológico, a saber, la propuesta por Hurtado Albir (2011: 269), constatamos que se ha empleado un amplio abanico de procedimientos a lo largo del proceso de subtitulación. A continuación, brindamos una somera sistematización de las técnicas de traducción presentes:

\begin{tabular}{|l|l|}
\hline Traducción literal & Hijo de puta = figlio di puttana \\
\hline Calco & $\begin{array}{l}\text { Joder = dannazione } \\
\text { Cojones = dannazione } \\
\text { ¿Qué carajos te pasa? = che diavolo ti } \\
\text { prende? }\end{array}$ \\
\hline Particularización & Putas = scarafaggi \\
\hline Ampliación lingǘstica & $\begin{array}{l}\text { Abre la puta boca = apri quella cazzo di } \\
\text { bocca } \\
\text { Coño = porca puttana }\end{array}$ \\
\hline Compresión lingüística & $\begin{array}{l}\text { Me cago en la puta = porca puttana } \\
\text { Vete a la mierda = fottiti } \\
\text { Empalado por el culo = impalarti }\end{array}$ \\
\hline Modulación & $\begin{array}{l}\text { ¿Qué cońo haces? = chi credi di essere? } \\
\text { Me tienes hasta los cojones = sono stufo } \\
\text { di queste stronzate }\end{array}$ \\
\hline Elisión & $\begin{array}{l}\text { No seas pesado, coño = non fare il } \\
\text { difficile } \\
\text { Callad, maricones = zitto! }\end{array}$ \\
\hline
\end{tabular}

10. Proporcionamos a continuación la definición que ofrece Rossi (2010) de doppiaggese: "quella forma d'italiano ibrida tra falsa colloquialità (ricca di calchi e stereotipi), pronuncia impeccabile e formalismo. Il nitore della pronuncia e l'impostazione teatrale delle voci dei 
Es interesante asimismo poner de relieve que contamos con elementos anafóricos (Hay maricones con suerte = alcuni sono fortunati), pues en la versión italiana se utiliza el pronombre indefinido para hacer referencia a algo que ya se ha enunciado (los maricones). Un caso parecido lo tenemos con "Yo quiero ver al marica bailar", subtitulado por Voglio vederlo ballare". Para evitar en italiano la repetición del sustantivo vulgar y despectivo marica, se emplea un deíctico.

\section{A modo de conclusión}

Para ir terminando, en este estudio --sin ningún ánimo de exhaustividadnos hemos propuesto analizar el tratamiento que reciben determinadas palabras y expresiones marcadas como vulgares o malsonantes en el trasvase interlingüístico realizado mediante el proceso de la subtitulación. Al tratarse de una modalidad particular de traducción audiovisual sujeta a varias limitaciones de tipo espacio-temporal, lo primero que en términos generales hemos tenido en cuenta ha sido la posibilidad de que en la versión subtitulada en italiano pudiesen faltar varios elementos léxicos presentes en la versión original. Cabe precisar que nuestro análisis solo se ha centrado en la localización de voces vulgares y malsonantes, de ahí que no podamos extender nuestras reflexiones a la totalidad de los ítems lingüísticos que conforman la miniserie. En lo que al objeto de nuestro artículo atańe, podemos afirmar que hemos localizado escasos ejemplos de supresión de información lingüística de la versión original, lo cual nos permite asegurar que los ítems groseros, malsonantes y vulgares han recibido a todos los efectos un tratamiento traductológico concreto.

Ahora bien, cabe plantearse qué se puede calificar como vulgar o malsonante a la altura del año 2021. Existen sin duda palabras y expresiones que hace diez o veinte años no podían formar parte de las conversaciones cotidianas e intercambios dialógicos más o menos informales por ser consideradas tabúes, pues ofendían al pudor, al buen gusto o a la religiosidad. Sin embargo, hoy día, nos guste o no, el lenguaje malsonante, vulgar y grosero forma parte de nuestra cotidianeidad (Fuentes Luque, 2014: 3) y cada vez más varias categorías de personas hacen un uso más abundante del registro vulgar, incluso en franjas de la población — los mayores por ejemplo— que tradicionalmente no dicen palabrotas.

Pues bien, si acudimos a un diccionario bilingüe, es probable que nos encontremos con que un lema marcado como vulgar en una edición confeccionada hace quince o más años ya no lo sea, porque su uso se ha venido extendiendo y estandarizando en el plano semántico ${ }^{11}$. No todas las lenguas

doppiatori sono garantiti dalla solida formazione tradizionale di questi ultimi (tra i protagonisti storici, Tina Lattanzi ed Emilio Cigoli), quasi tutti attori di professione e, fino a non molti anni fa, diplomati all'Accademia nazionale d'arte drammatica".

11. Excede el objetivo del presente artículo, pero sería interesante realizar un estudio sobre la marcación, en este caso de voces vulgares y malsonantes, y su evolución a lo largo de las ediciones y actualizaciones posteriores, con el fin de comprobar si determinadas palabras o expresiones marcadas como groseras o tabuizadas, lo siguen siendo en las versiones sucesivas. 
conciben la utilización del lenguaje vulgar y soez de la misma manera. Hay lenguas y culturas en las que por tradición las expresiones ofensivas, indecentes o groseras no se toleran en contextos de comunicación estándar, mientras que hay otras donde ya no causa ningún escándalo oír palabrotas. A pesar de ser el italiano y el español dos lenguas emparentadas a nivel histórico y filogenético, si tomamos en consideración la miniserie televisiva objeto de nuestro análisis, podemos afirmar que el recurso al lenguaje soez se da con más contundencia en español. A este respecto, cabe realizar una aclaración: no en todo el mundo hispanohablante se adopta del mismo modo el lenguaje vulgar. En la mayoría de los países de Latinoamérica, el hecho de utilizar el lenguaje vulgar no está bien visto y como también señala Pérez Fernández (2019: 98), la cultura latinoamericana está menos acostumbrada al empleo del lenguaje soez ${ }^{12}$. Además, siguiendo a Miquel Cortés (2004) en América Latina es frecuente la tendencia a la omisión y neutralización de expresiones con carácter soez. En la estela de lo anterior, García Aguiar y García Jiménez (2013) al abordar el doblaje para Hispanoamérica, comprueban la adopción de un variado y elevado abanico de estrategias de atenuación del lenguaje soez que las lleva a hablar de un español neutro. Las mencionadas estrategias apuntan, entre otras cosas, a atenuar la marcación diatópica, fenómeno típico a la hora de analizar las diferencias entre el español de América y el de España. Sin embargo, en la variedad peninsular el empleo de estas expresiones es un fenómeno cultural mucho más difundido y aceptado. Desde este punto de vista, la lengua italiana se coloca en una línea similar a lo mencionado en relación con el panorama del lenguaje soez en América Latina en un variado abanico de situaciones comunicativas, tanto formales como informales. Tampoco pretendemos generalizar excesivamente, ya que no contamos con un panorama lo suficientemente exhaustivo como para afirmar con contundencia y evidencia que la diferencia de uso del lenguaje soez es tan marcada entre el italiano y el español hablado en España. En lo referente al panorama italiano, en un estudio muy reciente sobre los insultos en el ámbito cinematográfico, Gargiulo (2020: 27) pone de manifiesto que el lenguaje soez es el reflejo de la evolución que la sociedad italiana ha venido experimentando a lo largo de las décadas.

Ahora bien, como observa Pérez Fernández (2020: 154), cada cultura cuenta con sus propios sistemas de referencia en lo que a la creación y expresión del lenguaje soez se refiere y, desde este punto de vista, el italiano y el español no son excepciones. Además, siendo la subtitulación una modalidad de transferencia de textos multimedia y multimodales de una lengua/cultura A a una lengua/cultura B, hay que prestar especial atención --a la hora del trasvase interlingüístico- a la combinación de la dimensión auditiva y de la visual, lo cual puede acarrear dificultades de orden traductológico. Aun

12. En el estudio de Fuentes Luque (2014), encontramos una interesante categorización de los principales sistemas de referencia del lenguaje tabú y soez que se suelen utilizar en algunas de las lenguas más comunes en el ámbito de la traducción audiovisual: sexo (anatomía, obscenidad); escatología (fluidos, sólidos, corporales, muerte); religión (blasfemia, profanación); familia (presentes y/o ancestros); nominalia (despectivos). 
conscientes de que la amplitud del corpus de expresiones con carácter soez y malsonante analizado no permite extraer conclusiones definitivas, creemos, de todas maneras, que, mediante el estudio presentado en este artículo, ha quedado corroborado que en italiano se produce un fenómeno de atenuación y de desintensificación de los términos y expresiones con carácter vulgar y soez con respecto al español peninsular. En este sentido, Ávila-Cabrera (2015: 16) apunta al fenómeno de la suavización a la hora de transmitir la carga ofensiva de determinadas palabras, lo cual está en línea con nuestro planteamiento.

Sentado lo anterior, no se puede infravalorar que las palabras o expresiones malsonantes del italiano y del español no siempre manifiestan la misma intención comunicativa, las mismas emociones o sentimientos (Di Vincenzo, 2020), de ahí que una conclusión general sea que la afinidad lingüística no garantiza una perfecta equivalencia traductológica en el plano pragmalingüístico, por lo que la traducción literal en contados casos cumple una función apropiada. Para confirmar o bien desmentir lo anteriormente expuesto, sería sin duda deseable y oportuno ampliar el corpus analizado y comprobar si se manifiestan las mismas tendencias a la hora de estudiar los resultados del proceso de traducción/subtitulación.

\section{Referencias bibliográficas}

Ávila-Cabrera, J. J. (2015). Propuesta de modelo de análisis del lenguaje ofensivo y tabú en la subtitulación. Verbeia, 0, 8-27. Recuperado de: https://journals.ucjc. edu/VREF/article/view/4067. [Consulta: 31-07-2021].

Bazzanella, C. (2020). Insulti e pragmatica: complessità, contesto, intensità. Quaderns d'Italià, 25, 11-26. Recuperado de: https://revistes.uab.cat/quadernsitalia/article/ view/v25-bazzanella. [Consulta: 29-07-2021].

Bermejo Calleja, F. (2016). La explicitación de la norma en lexicografía en la primera mitad del siglo XX. Artifara, 16, 115-133. Recuperado de: https://www.ojs.unito. it/index.php/artifara/article/view/1659. [Consulta: 28-07-2021].

Calvo Rigual, C. (2003). L'uso delle marche col, fam, pop e volg in dizionari italiani. Echenique Elizondo M. T., Wener R.O., Rojas Meyer E. y Aleza Izquierdo M. (Eds.), Lexicografia y Lexicologia en Europa y América. Homenaje a Günther Haensch en su 80 aniversario (p. 155-168). Madrid: Gredos.

Castillo Peña, C. (2007). Las marcas de uso en los modernos diccionarios bilingües espańol-italiano. San Vicente F. (Ed.), Perfiles para la historia y crítica de la lexicografía bilingüe del español (p. 39-58). Milano-Monza: Polimetrica.

Cundín Santos, M. (2002). La norma lingüística del español y los conceptos coloquial y vulgar en los diccionarios de uso. Revista de lexicografía, 8, 43-102.

Días Cintas, J. (2001). La traducción audiovisual: el subtitulado. Salamanca: Editorial Ambos Mundos.

Días Cintas, J. (2008). The Didactics of Audiovisual Translation. Amsterdam: John Benjamins.

Di Vincenzo, D. (2020). Análisis contrastivo español-italiano de términos y expresiones malsonantes en el registro coloquial del lenguaje cinematográfico. Tesis Doctoral, Universidad de Valladolid. Disponible en línea: https://uvadoc.uva.es/ 
bitstream/handle/10324/40604/Tesis1702-200310.pdf?sequence=1\&isAllowed=y. [Consulta: 31-07-2021].

Fontcuberta i Gel, J. (2001). La traducción en el doblaje o el eslabón perdido. Duro Moreno M. (Eds.), La traducción para el doblaje y la subtitulación (p. 299-313). Madrid: Cátedra.

Fuentes Luque, A. (2014). El lenguaje tabú en la traducción audiovisual: Límites lingüísticos, culturales y sociales". CVC E-Aesla, Rivista Digital de Lingüística Aplicada, 1, 1-11. Recuperado de: https://cvc.cervantes.es/lengua/eaesla/pdf/01/70. pdf. [Consulta: 31-07-2021].

García Aguiar, L. C. y García Jiménez, R. (2013). Estrategias de atenuación del lenguaje soez: algunos procedimientos lingüísticos en el doblaje para Hispanoamérica de la película "Death Proof". Estudios de Traducción, 3, 135-148. Recuperado de: https://revistas.ucm.es/index.php/ESTR/article/view/41995 [Consulta: 31-07-2021].

Gargiulo, M. (2020). Gli insulti cinematografici. I film degli anno Sessanta. Quaderns d'Italià, 25, 27-46. Recuperado de: https://revistes.uab.cat/quadernsitalia/article/ view/v25-gargiulo. [Consulta: 29-07-2021].

Garriga Escribano, C. (1994). La marca de 'vulgar' en el DRAE: de Autoridades a 1992. Sintagma, 6, 5-23.

Garriga Escribano, C. (2019). De nuevo sobre las marcas de uso, del pasado inmediato al futuro imperfecto. Sanmartín Sáez J. y Quilis Merín M. (Coords.), Retos y avances en lexicografía: los diccionarios del español en el eje de la variación lingüistica (p. 17-40). Revista de Estudios Lingüísticos. Valencia: Asociación Española de Estudios Lexicográficos.

Garzelli, B. (2020). La traducción audiovisual español-italiano. Películas y cortos entre humor y habla soez. Linguistic Insights, vol. 269, Bern: Peter Lang.

Gordón Peral, M. D. (2010). La caracterización lexicográfica de voces malsonantes en el diccionario monolingüe de aprendizaje del español. Ruhstaller S. y Gordón M. D. (Eds.), Diccionario y aprendizaje del español (p. 321-355). Berna-BerlínBruselas-Frankfurt-Nueva York-Oxford-Viena: Peter Lang.

Hurtado Albir, A. (2011). Traducción y Traductología. Introducción a la Traductología. (quinta edición revisada). Madrid: Cátedra.

Miquel Cortés, C. (2004). Traducción y (auto)censura: el caso de Kill Bill en España y Latinoamérica. Fòrum de recerca, 10.

Molina, L. y Hurtado Albir, A. (2002). Translation techniques revisited: a dynamic and functionalist approach. Meta, 47 (4), 498-512.

Nomdedeu Rull, A. (2011). Las voces malsonantes. San Vicente F., Garriga C. y Lombardini H. (Eds.), Ideolex. Estudios de lexicografía e ideología (p. 167-182). Milano-Monza: Polimetrica.

Orrù, P. (2020). “Capra sarai tu e anche maleducato!!”: insulto e interazione nei commenti Facebook. Quaderns d'Italià, 25, 65-82. Recuperado de: https://revistes.uab. cat/quadernsitalia/article/view/v25-orru. [Consulta: 29-07-2021].

Pavesi, M. (2006). La traduzione filmica. Aspetti del parlato doppiato dall'inglese allitaliano. Roma: Carocci.

Pavesi, M. y Malinverno, A. L. (2000). Usi del turpiloquio nella traduzione filmica. Taylor C. (Ed.), Tradurre in cinema. Atti del Convegno (Trieste, 29-30 novembre 1996) (p. 75-90). Trieste: EUT Edizioni Università Trieste.

Pérez Fernández, L. M. (2019). La traducción del lenguaje soez: diferencias entre la traducción al español de Espańa y de Latinoamérica en la película Sausage Party. 
Estudios de Traducción, 9, 97-111. Recuperado de: https://revistas.ucm.es/index. php/ESTR/article/view/65704. [Consulta: 30-07-2021].

Pérez Fernández, L. M. (2020). Análisis comparativo de los sistemas de referencias del lenguaje soez: el caso de la serie de animación Rick y Morty. Estudios Interlingüisti$\cos , 8,154-173$. Recuperado de: https://estudiosinterlinguisticos.files.wordpress. com/2020/11/perez-fernandez-lucila-maria.pdf. [Consulta: 30-07-2021].

Rossi, F. (2006). Il linguaggio cinematografico. Roma: Aracne.

Rossi, F. (2010). Doppiaggio e lingua. In Enciclopedia dell'italiano. Recuperado de: https://www.treccani.it/enciclopedia/doppiaggio-e-lingua_(Enciclopediadell'Italiano). [Consulta: 26-07-2021].

Toledano, C. (2002). Algunas consideraciones generales sobre la traducción, la obscenidad y la traducción de la obscenidad. Revista canaria de estudios ingleses, 44, 217-232.

Trovato, G. (2019). Una aproximación a la traducción italiano > español desde la variación lingüística: la dimensión diatópica en la prosa de Andrea Camilleri. Inverbis, anno IX, número 1, 361-384.

Zamora Muñoz, P. (2015). Pautas de traducción de las unidades fraseológicas tabuizadas en el doblaje fílmico italiano-español. Mogorrón Huerta P. y Navarro F. (Eds.), Fraseología, Didáctica y Traducción (p. 321-338). Frankfurt: Peter Lang.

Zamora Muńoz, P. (2016). Las secuencias interrogativas-exclamativas italianas con cazzo en el hablado fílmico italiano y su doblaje al español: técnicas aplicadas y normas de traducción. Hermeneus, 18, 315-339.

Zamora Muñoz, P. (2018). La traducción de minchia, término vulgar y marcado en diatopía, en el doblaje del italiano al español. Mogorrón Huerta P. y AlbaladejoMartínez A. (Eds.), Fraseología, Diatopía y Traducción / Phraseology, Diatopic Variation and Translation (p. 155-176). Amsterdam/Philadelphia: John Benjamins Publishing Company.

\section{Webgrafía}

Real Academia Española, Diccionario de la Lengua Española [https://dle.rae.es/]

CLAVE, Diccionario de Uso del Español Actual [http://clave.smdiccionarios.com/app. php]

Treccani, Vocabolario della Lingua Italiana [http://www.treccani.it/vocabolario/]

Hoepli, Grande Dizionario Italiano [https://www.grandidizionari.it/dizionario_ italiano.aspx]

Zanichelli, Il Grande Dizionario di Spagnolo (Dizionario Spagnolo-Italiano / ItalianoSpagnolo), [http://dizionari.zanichelli.it/dizionarionline/online.php?p=ARQUES\#] 
